\title{
Investigating Marital Infidelity from the Perspective of Payame Noor and Azad Universities' Students in Bileh Savar County in 2015
}

\author{
Mohsen Alayi ${ }^{1}$ \& Azam Faridi ${ }^{2}$ \\ 1 Assistant Professor of Sociology, Payam Noor University(PNU), Faculty member of PNU, Iran \\ ${ }^{2}$ M.A. graduate student in Sociology of Tehran Payame Noor University, Iran \\ Correspondence: Mohsen Alayi, Assistant Professor of Sociology, Payam Noor University(PNU), Faculty \\ member of PNU, Iran. E-mail: moalaei@gmail.com; azamfffa@yahoo.com
}

Received: January 15, 2017

Accepted: January 30, 2017

Online Published: July 30, 2017

doi:10.5539/mas.v11n8p124

URL: https://doi.org/10.5539/mas.v11n8p124

\begin{abstract}
Infidelity is one of the problems which families are involved in and it goes forward to complete separation. Of course, this problem existed long time ago, with this difference that infidelity and polygamy were common categories in families in the past and they were a privilege especially for men. Sometimes, even women themselves were looking for a wife for their husband. However, at the present time, polygamy is not considered as a privilege and value and even women are not willing to share their husband with another woman. This subject has become a problem in families. The research population consisted of students (male and female) of Payame Noor and Azad Universities in Bileh Savar County. All students of Payame Noor University were 500 and students of Azad University were 1000. Since there were no accurate statistics of married students at both universities, and also due to the lack of financial ability and high costs of research analysis, 150 students were randomly selected as the sample of research. Survey research method and questionnaire were used for data collection. Statistical methods were applied in the forms of descriptive statistics (frequency table, percent, charts) and referential statistics (Pearson test, t-test).
\end{abstract}

Keywords: economic problems, emotional dissatisfaction, age, sexual needs, social network (virtual), satellite, low level of religiosity, infidelity

\section{Introduction}

\subsection{Statement of the Problem}

In the present study, marital infidelity is investigated from the perspective of Payame Noor and Azad Universities' students in Bileh Savar County in 2015.

Family is the cornerstone of every great human society and plays a critical role in strengthening social relationships and growing members of society. Efforts to strengthen family relationships provide the way for moral health and public welfare. Family is the most important factor in the socialization of individuals, the most important and appropriate center for meeting emotional needs of individuals and a social status which its formation has been emphasized by Islam. Undoubtedly, marriage is the biggest and most important event of every human life. Marriage is a long-lasting social tradition which is considered as a sacred and important event among Muslims in general and specifically among Iranian people since ancient times. It is a holy covenant by which a man and woman establish their own common life and promise to be sympathetic to each other. Marriage is a natural desire endorsed by all human societies and religions. Especially, Islam invites its followers to marry and also considers it essential (Taheri, 2010: 68).

Infidelity is a reality in the new world. In 1948, Alfred Kinsey collected early data related to the prevalence of marital infidelity. He concluded that among 3088 men and 2000 women in the US, respectively $50 \%$ and $26 \%$ had marital infidelity. During the 1950s, a lot of theoretical foundations were released about marital infidelity and until the 1970s and 1980s, several studies were conducted in this area. Concerns about AIDS and risky sexual behaviors led to special attention to such research; as a result, the related literature increased significantly (Jeanfreau, 2009). There are no statistics published about the prevalence of marital infidelity in Iran, however, some studies have pointed out such matters; for example, the highest rate of family-related homicides which is 30 percent is related to women killed by their husbands because of adultery and suspicion. On the other hand, 22 
percent of family homicides is related to men killed by their wives that 40 percent of murdered men killed by their wives with the help of their lover (Kalhor, 2007). Robert Merton believes that society make individual engage in deviant acts. In his opinion, deviant behavior is the result of certain socio-structural pressures which make people engage in deviant acts. Merton states that modern industrial societies emphasize on material success in life which is manifested in the forms of accumulation of wealth and scientific education as the most important goals of a person's life and criteria of human dignity. To achieve these goals accepted in society, it requires valid tools which are not available to a group of people; it means that society has been structured in the way that people of the lower class have fewer opportunities to achieve their dreams. Since these goals have become the main objectives of all people's lives (rich and poor), a person who does not have access to legitimate tools makes use of illegitimate means to achieve his goals under the pressure of the society (Merton, 1968: 185-248).

\subsection{Main Question of the Research}

What are the causes of infidelity in marital relationships from students' perspective?

\subsection{Secondary Questions of the Research}

1. Have economic problems impact on marital infidelity?

2. Has emotional dissatisfaction impact on marital infidelity?

3. Has couples' age impact on marital infidelity?

4. Have sexual needs impact on marital infidelity?

5. Have social networks (virtual) impact on marital infidelity?

6. Has low level of religiosity impact on marital infidelity?

\section{Theoretical Framework of the Research}

\subsection{Anomie Theory}

Merton rejects any individualistic and psychological explanation on the issue of deviance and considers it as a category affected by the structure of the society. He states that structural conditions are the main cause of deviations. In his opinion, one of the main elements of society structure is to provide standardized methods of action, namely the tools and norms to achieve the objectives. He considers objectives and values accepted in the society as the other main elements. When there is coordination between these two main elements, he considers a social system as a "balanced" one; in the way that people can achieve accepted objectives through legitimate tools, means and ways in the society called "conformity" method. However, when there is no such coordination between objectives and means to achieve them, and some people cannot achieve their accepted goals through accepted means in the society, they feel unsatisfied and try to follow illegitimate and unacceptable ways in society like deviant ones such as running away from home and asking unreliable ones for help (Marefat Journal, No. 56, p: 93).

\subsection{Theory of Stigma}

According to the theory of stigma, individuals' behaviors are shaped by the others' reactions and when they label personal actions as deviant ones, person is forced to play a deviant role.

Theory of stigma emphasizes that labeling behaviors can play an important role in the occurrence and continuation of deviant behaviors. When people are labeled as followers of deviant behaviors like guilty and addicted ones react to such behaviors frequently to meet what is expected (Solasi, 2007: 114).

\subsection{The Doctrine of Deterrence}

The doctrine of deterrence emphasizes on formal social control which is applied by judges and other law enforcement agencies. The underlying assumption in this theory is that basically, human beings behave rationally and an input-output analysis is used in occurrence any deviant behavior; when the cost of committing is more than its profit, they will refrain from such behaviors. Hence, the underlying assumption is that punishment which is social control through arrest, prosecution, imprisonment, or execution of criminals prevents committing crimes and lack of punishment leads to deviance. Of course, when intensity, certainty and speed categories are effectively observed in imposing penalties in general; therefore, punishments deter people from committing crimes (infidelity) and also when they are served in particular, the deviant person (traitor in the present study) stops his deviant behavior. The hypothesis is that if the intensity, certainty and speed of penalties are highly observed, their deterrent power will be more (Tello, 2001: 29). 


\subsection{Social Action and Anomie}

Parsons believes that the proper function of cultural, social, personal and economic sub-systems and relationship and interaction among them are controlling factors of every society and causes of survival and sustainability of social system. In contrast, lack of balance and order in each of sub-systems threatens community life and provides the way for deviant behavior (infidelity). Parsons claims that institutions and social organizations are considered as enforcement agents and socializing means of behavioral patterns and institutionalizing them. If organizational socialization and institutions such as family, school and mass media do not have the required efficiency, the society encounters with social disorganization leading to prevalence of deviant behavior in society especially infidelity. Accordingly, Parsons considers deviance as a phenomenon resulted from disorganization and also as an activity which is the product of any incomplete solidarity among members of social world; a phenomenon that at the same time can be associated with institutions and individuals that have been placed in an area with no conjunction with others, and finally, it becomes either a new conformity or a survived category as a pressure source within the existing social system. It may be destroyed by the balance and harmony achieved in the society in future (Ritzer, 2009).

\subsection{Exchange Theory}

Homans is one of the theorists of exchange theory who pays attention more on exchange between two persons and believes that social exchange is based on self-interest and a combination of economic and psychological needs. He has tried to make his propositions based on psychological principles. He explains different propositions involving the base of his exchange theory. These theorems are as follows: Success, value, stimulus, deprivation-satiation, rationality, and aggression-approval propositions (Ritzer, 2009: 427).

Generally, exchange theory can be applied in explaining maximization of profit in decisions related to divorce and infidelity. People who decide to divorce need to assess benefits of their own marriage in compared with other marriages and also in compared with life after divorce. The theorists of family development theory have admitted that social norms determine the time and sequence of events occurred in family and deviation from the norms ultimately leads to dissolution of the family (Klein \& White, 1996).

\subsection{Theory of Human Needs}

People have objectives and needs in their personal and social life who try to achieve their objectives and meet their needs. One of human needs which plays a very important role in personal and social life as well as his evolution is sexual need. Some people apply infidelity strategy to satisfy themselves when they are in trouble to meet their sexual needs in relation with their wives and husbands (Enayat, 2002).

\subsection{Shaming Theory}

John Braithwaite believes that conformity in society is because of controlling people by different factors. One of them is shaming factor by different ways.in his opinion, shaming strategy is a kind of social disapproval against specific behaviors in order to stimulate the sense of remorse in guilty person. Braithwaite discusses about disintegrative and reintegrative shaming which will explained as follows:

Disintegrative shaming: it takes place when the deviant person is punished, labeled and deprived and finally isolated from the society.

Reintegrative shaming: this theory explains that the feelings of deviant one can be understood and his deviant behavior is ignored and is treated with respect. In fact, this type of shaming creates a sense of guilt and eventually prevents him from committing deviant acts and his return to the group is welcome.

Of course, it should be noted that regarding infidelity as a form of deviance in Iranian society, disintegrative shaming is applied among deviant women and reintegrative shaming among deviant men (Tello, 2001: 28-29; Kahan, 1997; Braithwaite, 1989).

\subsection{Social Learning Theory}

An important and permanent member of all sociological theories is probably the category which is called social learning by Bandura. Bandura believes that normal and abnormal behaviors have rooted in people's learning environment. In his opinion, learning is usually achieved under direct conditions of individual observations (punishment and encouragement). It can be said that learning is the result of personal experiences or is derived from positive outcomes through behavior of other people. Therefore, a person who witnesses the deviant behavior of one of his parents (father or mother) in his father's family, or commits such infidelity in his own life will be encouraged to continue this process, if he is not punished (Parsa, 2004: 217). 


\subsection{Cultural Transmission Distortions}

Regarding how cultural distortions are transmitted, Sutherland believes that deviant behavior is learned through interaction with others (deviant ones) like other social behaviors. According to this perspective, deviant behavior has neither hereditary nor psychological origin and person learns it from others; as united members of a group accept norms and cultural values of the group and society through connection with compatible individuals. Therefore, friends and main groups not only have effect on people's conformity and norm breaking, but also have critical effect on the type of deviant behaviors and crimes committed by individuals (Ghojoghinejad, 2009: 111). Edwin Sutherland's theory of differential association is the most famous theory among theories of socialization or learning theories in social distortions discussions (Sarvestani, 2010: 48). Edwin Sutherland believes that deviant behavior is learned through "relationship with others" with "differential association" which means having social relationships with certain types of people as "criminals". In his opinion, to be a criminal, a person must first learn how a crime is committed (Solasi, 2007: 177).

\section{Network Theory}

Network theory is raised against normative theory. According to the perspectives of network theorists, normative views emphasize on culture and socialization processes and values and norms are internalized in people. In normative perspective what keeps people together is a series of common ideas. Network theory rejects such perspective and expresses that casual patterns which connect people together should be studied. If both husband and wife belong to such networks which are maintained, marriage is simply imposed on the existing relationships; hence, Couples move forwards activities in outside and other people forwards inside home. In this case, the rigid and inflexible separation of roles becomes possible because couples will be able to be supported by elements out of family (Segalen, 2001).

\subsection{Differential Reinforcement}

Robert Burgess and Ronald Akers question Sutherland's theory according to the reinforcement theory stating that continuing or stopping any behavior depends on the encouragement or punishment; it means that encouragement leads in continuing a certain behavior and punishment prevents it. In other words, they claim that association with ones who have deviant behaviors does not make someone deviant. People prefer distortions to conformity when their proportion is more satisfactory to conformity with higher frequency and possibility. According to differential reinforcement, Burgess and Akers believe that if some elements produce reinforcement forces, the element has the highest probability that produces the highest reinforcement in terms of quantity, frequency and probability (Burgess\& Akers, 1966). Therefore, according to them, intervention of third variable differential reinforcement in differential association environment is the main cause of distortion.

\subsection{Strain Theory}

Strain theory is one of the sociological theories raised in issues related to infidelity. The central question in this theory as any other theory in the positivism paradigm is that why people have deviant behaviors. The general answer to this question is that there are some factors in society which put people under pressure and make them behave inappropriately (Agnew, 1995). This deviant behavior is shown in various forms; one of them is marital infidelity. When a person is faced with different pressures and strains in marital life, he will have to commit infidelity. Robert Merton states that this kind of strain is caused by the inability of a person to achieve acceptable social objectives; Albert Cohen considers the category of failure to reach a high position as the cause of strain; Colward \& Ohlin regards lack of illegitimate opportunities to achieve the targets as cause of strain and deviant behaviors (Tello, 2001: 17).

\subsection{Differential Legitimate Opportunities}

Robert Merton believes that society makes people behave inappropriately. In his opinion, distortion is the result of certain socio-structural strains which force people to show deviant behaviors (Merton, 1968: 185-248). He claims that industrial societies emphasize on material success in life which is manifested in the forms of accumulation of wealth and scientific education as the most important goals of a person's life and criteria of human dignity. To achieve these goals accepted in society, it requires valid tools which are not available to a group of people; it means that society has been structured in the way that people of the lower class have fewer opportunities to achieve their dreams. Since these goals have become the main objectives of all people's lives (rich and poor), a person who does not have access to legitimate tools makes use of illegitimate means to achieve his goals under the pressure of the society. Of course, he emphasizes that all people don not react similarly against social strains due to the lack of legitimate opportunities to achieve their goals and all people of the lower class do not show deviant behaviors to achieve acceptable social objectives and everyone makes himself 
compatible with the environment. He explains that a group of people in the lower class is innovative and makes use of illegitimate means to be in abnormal compatibility with the environment (which is the main theme of strain theory). A group of radicals and revolutionaries behaves inappropriately against unattainable objectives and social legitimate means and introduces new objectives and means to change social structure. Some people also have to abandon acceptable objectives and social legitimate means to achieve them and leave the society. These three groups of innovators, rebels and those who leave the society have chosen deviant and norm breaking behaviors to be compatible with environment and society which have restricted their access to social accepted and legitimate means (Merton, 1968: 190-210).

\subsection{Differential Illegitimate Opportunities}

Colward \& Ohlin claim that Merton assumption stating that the people of lower class have fewer legitimate opportunities to achieve their socially acceptable objectives is correct; however, this assumption that these people show deviant behavior successfully and automatically when facing with no legitimate opportunities is not correct. Because the members of lower classes also encounter differential illegitimate opportunities after facing with differential legitimate opportunities. In other words, many members of lower classes have less opportunity than others even in their own class to achieve successfully their objectives through abnormal ways; therefore, although, some members of the lower class are under pressure to show deviant behavior, they cannot necessarily behave abnormally, because there is a lack of illegitimate opportunities (means) to show deviant behaviors (Colward \& Ohlin, 1960).

\subsection{Status Frustration}

According to Cohen, incompatibility of objectives and means will not lead to deviant behavior by itself, unless an intervening variable such as failure and status frustration be added into the equation. In other words, Cohen and Merton believes that members of the lower class participate in abnormal activities much more likely than others, because society cannot help them achieve their dreams; hence, if Merton claims that the gap between objectives and means causes distortions, Cohen states that the gap between objectives and means will cause distortions through status frustration (Cohen, 1995).

According to Philip Seven, mind and interpretative sociologist, human being has authority and internal and external forces restrict individuals' choice; however, a person makes a choice within restrictions and individual's choice is the product of his subjective meanings of "situation" (Bokharayi, 2010: 32).

\subsection{Religion Theories}

Paul Radin: Religion is composed of two parts: the first part is easily defined, it is certain and particular feeling; and the second part includes actions, customs, beliefs and certain concepts associated with these feelings. A belief that is deeply associated with a certain feeling is a belief in spirits beyond people control which is assumed more powerful than human beings and controls whatever human beings require under pressure on behalf of it in their life (Radin, 1957: 3).

\subsection{Durkheim's Theory}

Durkheim identified religion as the main source of morality and social cohesion. In his opinion, collecting people in religious ceremonies strengthens religious beliefs and also leads to enthusiastic and warm feelings which improve the relationship among people. Hence, religious rituals lead to solidarity of society by strengthening collective beliefs and morals as well as establishing relationships among participants. The function of religion in the society is to integrate and consolidate it. In a book titled "About the definition of the phenomenon of religion", he regards an agent role for religion, it means that practices and religious convictions make social morality consistent. Therefore, the sociology of religion studies the social forces which have overcome the believer as well as conditions in which religious feelings are aroused. According to Durkheim, the evolution of religion parallels and corresponds to the evolution of morality. Along with religions, ethical and legal rules become universal and inclusive. There is something of ethics in religion and something of religion in ethics and the current ethical life is virtually full of religious matters. Since ethics have been considered as sign of religion over the history, it is impossible to be entirely devoid of this character, because in this case, its life will end.

\subsection{Marx's Theory}

According to Marx, religious feeling is a social product. Religion is essentially the product of class society. Marx's thoughts about alienation are part of his overall theory about alienation in class societies. He states that religion is the product of alienation and represents class interests. It is also a means of deception and oppression in lower class of the society as well as a protest against oppression and a kind of submission and comfort against 
oppression.

Power and capabilities of man are observed in God and God appears as a complete and almighty one. Accordingly, man creates religion not religion the man. In other words, religion is the human consciousness which has not yet found itself or has lost itself again. Marx claims that religious grief is the expression of real grief and also a protective shield against real grief. Religion is the oppressed aspiration and heart of the heartless world, just like a case in which a spirit makes a depressed position live. Religion is the opium of the people. Religion is nothing but the imaginative reflection of external forces that govern daily life and earthy forces appears in the form of supernatural forces in human minds by its help (Tavasoli, 1993; Eliade, 1994).

\subsection{Sexual Theories}

\subsection{Sexual Relations}

There have been unpleasant "sexual relations" in the most primitive human societies. However, how to remove the sexual chaos and turn it to marriage is an important category. Since women were more sensitive and gentle creatures than men, they removed conditions related to sexual chaos. Although, religious desires encouraged them, they resorted to coercive force and ended this situation.

Women invented the first wedding and overcame violence and sexual chaos (Farbod, 2004: 190).

The family is a social system and social progress and development are reflected within the family; therefore, the family is considered as a changing and social phenomenon.

Rollomay believes that sexual love is valuable because of improving self-awareness, experiencing compassion and kindness, increasing pride and self-expressiveness and experiencing orgasm. Sometimes, sex and love are mutually and appropriately reinforcing and improving each other (Rabani, 2002: 16).

Intimacy in sexual relations is the result of loving each other. This ability demonstrates deep self-awareness and knowledge of loving another one and romantic relationships act as catalyst.

\subsection{Differential Association Theory}

Edwin Sutherland's theory of differential association is the most famous theory among theories of socialization or learning theories in social distortions discussions. The main point in Sutherland's theory is that people show deviant behaviors because the number of their deviant contacts is more than their non-deviant contacts. The difference in people's interaction with those who have distorted ideas in compared with those who have conformity ideas (more contact with distorted ideas and ones with deviant behavior) is the main reason of their deviant behavior. A summary of Sutherland's approach to the category of deviant behavior is presented as follows due to its great importance.

1. Deviant behavior is learned. It is neither a hereditary character nor the result of low IQ or brain damage and something like that.

2. Deviant behavior is learned in interaction with others.

3. The main part of learning deviant behaviors takes place within the group and mass media and press play the secondary role.

4. Learning deviant behaviors involves learning specific wrongdoing techniques and trends and direction of certain motives and attitudes

5. Certain trends and direction of motives and attitudes are learned through definitions against norms and definitions which approve norms.

6. Everyone commits deviant acts because of high frequency of definitions which approve crime in compared with definitions approving conformity with norms. This point is the key issue in the theory of Sutherland.

7. Differential associations may be different in terms of frequency, duration, intensity and preference.

8. The process of learning deviant behaviors through interaction with those with deviant behaviors and those with conformity ideas has similar mechanism with other types of learning.

9. Deviant behavior which is the manifestation of needs and general values cannot be explained by the same general needs and values (Sutherland \& Cressy, 1966: 77-83).

\section{Research Hypothesis}

1. There is a relationship between economic factors and marital infidelity. 
2. There is a relationship between emotional dissatisfaction and marital infidelity.

3. There is a relationship between age factors and marital infidelity.

4. There is a relationship between sexual needs and marital infidelity.

5. There is a relationship between social networks, satellite and marital infidelity.

6. There is a relationship between the low level of religiosity and marital infidelity.

\section{The Method of Research}

Due to the nature of the research, mainly a directed survey method, and in some cases library research method were used for data collection.

\section{Information Collection Tools}

Data are collected through survey method and self-designed questionnaires from two universities and are analyzed using SPSS advanced statistics in two parts of descriptive and inferential findings. Findings showed that variables of economic problems, emotional dissatisfaction, age, sexual needs, social network (virtual) and satellite are considered as factors affecting marital infidelity in Beleh Savar County.

\section{Statistical Population and Sample}

All students of Payame Noor University were 500 and students of Azad University were 1000. Since there were no accurate statistics of married students at both universities, and also due to the lack of financial ability and high costs of research analysis, and limited number of analytical units of the research, 150 students were randomly selected as the sample of research.

\section{Sampling Method}

Random sampling was used in the present study.

\section{Data Collection Tools}

There are different ways to collect data such as observation, interviews, questionnaires and etc. Because of benefits of questionnaire and the concordance between these benefits and the purposes of the research, questionnaires were used as the only tools to collect information in the present study. Questionnaire has been prepared using Likert scale (strongly agree, agree, somewhat disagree, strongly disagree).

Inferential Findings

Table 1. Results of Pearson correlation coefficient to determine the relationship between economic factors and infidelity

\begin{tabular}{lll}
\hline Pearson Test & Marital Infidelity & Economic Factors \\
\hline Pearson Correlation & 1 & 0.014 \\
Significant Level & 0 & 0.954 \\
Total & 150 & 150 \\
\hline
\end{tabular}

Since the dependent variable (marital infidelity) and independent variable (economic factors) are both interval, Pearson correlation test is used. This test has been measured in $99 \%$ confidence interval. Significance level is equal to 0.954 . $(\mathrm{Sig}=0.954)$ indicating that there is no significant relationship between marital infidelity and economic factors. According to the information shown in table, null hypothesis is confirmed and hypothesis 1 is rejected.

Table 2. Results of Pearson correlation coefficient to determine the relationship between emotional dissatisfaction factors and infidelity

\begin{tabular}{lll}
\hline Pearson Test & Marital Infidelity & Emotional Dissatisfaction \\
\hline Pearson Correlation & 1 & 0.791 \\
Significance Level & 0 & 0.000 \\
Total & 150 & 150 \\
\hline
\end{tabular}

Since the dependent variable (marital infidelity) and independent variable (emotional dissatisfaction) are both interval, Pearson correlation test is used. This test has been measured in $99 \%$ confidence interval. Significance 
level is equal to 0.000 . ( $\mathrm{Sig}=0.000)$ indicating that there is a significant relationship between marital infidelity and emotional dissatisfaction. Also Pearson correlation is equal to 0.791 indicating that there is a strong and direct relationship among variables; therefore, according to the information shown in table, null hypothesis is rejected and hypothesis 1 is confirmed.

In other words, the test results show that emotional dissatisfaction has a significant effect on marital infidelity and according to the information shown in table, when the average rate of emotional dissatisfaction increases, the rate and level of marital infidelity will also increase.

Table 3. Results of Pearson correlation coefficient to determine the relationship between age factors and infidelity

\begin{tabular}{lll}
\hline Pearson Test & Marital Infidelity & Age \\
\hline Pearson Correlation & 1 & 0.700 \\
Significance Level & 0 & 0.001 \\
Total & 150 & 150 \\
\hline
\end{tabular}

Since the dependent variable (marital infidelity) and independent variable (age) are both interval, Pearson correlation test is used. This test has been measured in $99 \%$ confidence interval. Significance level is equal to 0.000. ( $\mathrm{Sig}=0.000)$ indicating that there is a significant relationship between marital infidelity and age factors. Also Pearson correlation is equal to 0.700 indicating that there is a strong and direct relationship among variables; therefore, according to the information shown in table, null hypothesis is rejected and hypothesis 1 is confirmed.

In other words, the test results show that age factor has a significant effect on marital infidelity and according to the information shown in table, when the average rate of age increases, the rate and level of marital infidelity will also increase.

Table 4. Results of Pearson correlation coefficient to determine the relationship between sexual needs and infidelity

\begin{tabular}{lll}
\hline Pearson Test & Marital Infidelity & Sexual Needs \\
\hline Pearson Correlation & 1 & 0.626 \\
Significance Level & 0 & 0.003 \\
Total & 150 & 150 \\
\hline
\end{tabular}

Since the dependent variable (marital infidelity) and independent variable (sexual needs) are both interval, Pearson correlation test is used. This test has been measured in $99 \%$ confidence interval. Significance level is equal to 0.003 . ( $\mathrm{Sig}=0.003)$ indicating that there is a significant relationship between marital infidelity and sexual needs. Also Pearson correlation is equal to 0.791 indicating that there is a strong and direct relationship among variables; therefore, according to the information shown in table, null hypothesis is rejected and hypothesis 1 is confirmed.

In other words, the test results show that sexual needs factor has a significant effect on marital infidelity and according to the information shown in table, when the average rate of sexual needs increases, the rate and level of marital infidelity will also increase.

Table 5. Results of Pearson correlation coefficient to determine the relationship between virtual space and infidelity

\begin{tabular}{lll}
\hline Pearson Test & Marital Infidelity & Virtual Space \\
\hline Pearson Correlation & 1 & 0.530 \\
Significance Level & 0 & 0.016 \\
Total & 150 & 150 \\
\hline
\end{tabular}

Since the dependent variable (marital infidelity) and independent variable (virtual space) are both interval, Pearson correlation test is used. This test has been measured in $99 \%$ confidence interval. Significance level is equal to 0.016. $(\mathrm{Sig}=0.016)$ indicating that there is a significant relationship between marital infidelity and 
virtual space. Also Pearson correlation is equal to 0.530 indicating that there is a strong and direct relationship among variables; therefore, according to the information shown in table, null hypothesis is rejected and hypothesis 1 is confirmed.

In other words, the test results show that virtual space has a significant effect on marital infidelity and according to the information shown in table, when the average rate of virtual space factor increases, the rate and level of marital infidelity will also increase.

Table 6. Results of Pearson correlation coefficient to determine the relationship between low level of religiosity and infidelity

\begin{tabular}{lll}
\hline Pearson Test & Marital Infidelity & Low Level of Religiosity \\
\hline Pearson Correlation & 1 & 0.542 \\
Significance Level & 0 & 0.014 \\
Total & 150 & 150 \\
\hline
\end{tabular}

Since the dependent variable (marital infidelity) and independent variable (low level of religiosity) are both interval, Pearson correlation test is used. This test has been measured in $99 \%$ confidence interval. Significance level is equal to 0.014. ( $\mathrm{Sig}=0.014)$ indicating that there is a significant relationship between marital infidelity and low level of religiosity. Also Pearson correlation is equal to 0.542 indicating that there is a strong and direct relationship among variables; therefore, according to the information shown in table, null hypothesis is rejected and hypothesis 1 is confirmed.

In other words, the test results show that low level of religiosity has a significant effect on marital infidelity and according to the information shown in table, when the average rate of low level of religiosity factor increases, the rate and level of marital infidelity will also increase.

There is a significant difference in marital infidelity between men and women.

Table 7. Mean and standard deviation related to infidelity from the perspective of students between men and women

\begin{tabular}{lllll}
\hline Sex & Number of People & Mean & Standard Deviation & Standard Error of the Mean \\
\hline Woman & 50 & 38.4123 & 5.00586 & 0.46884 \\
Man & 100 & 39.7907 & 5.64258 & 0.49680 \\
\hline
\end{tabular}

Table 8. Results of Levene and independent t-tests and one-way analysis of variance related to infidelity from the perspective of students between men and women

\begin{tabular}{|c|c|c|c|c|c|c|c|c|}
\hline \multirow[b]{3}{*}{$\begin{array}{l}\text { Variance } \\
\text { groups }\end{array}$} & \multirow[b]{3}{*}{ between } & \multirow[b]{3}{*}{ two } & \multicolumn{2}{|c|}{ Levene Test } & \multicolumn{4}{|c|}{ Independent t-test } \\
\hline & & & $\mathrm{F}$ & $\begin{array}{l}\text { Significance } \\
\text { Level (Sig) }\end{array}$ & $\mathrm{t}$ & $\begin{array}{l}\text { Degree of } \\
\text { Freedom (df) }\end{array}$ & $\begin{array}{l}\text { Significance } \\
\text { Level (Sig) }\end{array}$ & Mean \\
\hline & & & 0.134 & 0.714 & -2.003 & 149 & 0.046 & -0.37842 \\
\hline $\begin{array}{l}\text { Variance } \\
\text { groups }\end{array}$ & within & two & & & -2.018 & 149.995 & 0.045 & -0.37842 \\
\hline
\end{tabular}

According to Levene test, significance level is equal to 0.714 ( $\mathrm{Sig}=0.714)$. In other words, the variance between two groups is the same. According to the results obtained from independent t-test in $95 \%$ confidence interval, significance level is equal to $0.046(\mathrm{Sig}=0.046)$ indicating that there is a significant difference between two groups. Also, $\mathrm{t}=-2.003$ and $\mathrm{df}=241$ indicating that there is a significant difference between the average rate of social vitality in women and men; therefore, null hypothesis is rejected and hypothesis 1 is confirmed. According to the information related to one-way variance analysis shown in the table, the average rate of marital infidelity in men is more than women's.

Table 9. Results of mean and standard deviation related to marital infidelity among students of two universities

\begin{tabular}{lllll}
\hline Sex & Number of People & Mean & Standard Deviation & Standard Error of the Mean \\
\hline Woman & 50 & 38.4123 & 5.00586 & 0.46884 \\
Man & 100 & 39.7907 & 5.64258 & 0.49680 \\
\hline
\end{tabular}


Table 10. Results of Levene and independent t-tests and one-way analysis of variance related to marital infidelity among students of two universities

\begin{tabular}{|c|c|c|c|c|c|c|}
\hline \multirow{4}{*}{$\begin{array}{l}\text { Variance between two } \\
\text { groups } \\
\text { Variance within two }\end{array}$} & \multicolumn{2}{|c|}{ Levene Test } & \multicolumn{4}{|c|}{ Independent t-test } \\
\hline & $\mathrm{F}$ & $\begin{array}{l}\text { Significance } \\
\text { Level (Sig) }\end{array}$ & $\mathrm{t}$ & $\begin{array}{l}\text { Degree of } \\
\text { Freedom (df) }\end{array}$ & $\begin{array}{l}\text { Significance } \\
\text { Level (Sig) }\end{array}$ & Mean \\
\hline & 0.956 & 0.329 & -12.532 & 149 & 0.127 & -1.06 \\
\hline & & & -1.527 & 149.274 & 0.128 & -1.06 \\
\hline
\end{tabular}

According to Levene test, significance level is equal to 0.329 ( $\mathrm{Sig}=0.329)$. In other words, the variance between two groups is the same. According to the results obtained from independent t-test in $95 \%$ confidence interval, significance level is equal to 0.127 ( $\mathrm{Sig}=0.127$ ) indicating that there is no significant difference between students of Payame noor and Azad universities; therefore, null hypothesis is confirmed and hypothesis 1 is rejected. According to the information related to one-way variance analysis shown in the table, the average rate of marital infidelity does not differ among various universities and the type of university has no effect on marital infidelity.

\section{The Results Obtained from Descriptive Findings and Analysis of Hypotheses}

Infidelity is one of the basic concepts in marital life. Committing infidelity by either the man or woman is condemned in human schools and religions. Infidelity is raised as a social issue. In the present study, factors affecting marital infidelity were measured. In modern era and industrial societies, marital infidelity has reached its minimum rate. Being explicit and lack of cumbersome biases are the most reasons of this issue. In terms of divorce, couples separate and marry easily, and divorce has not a long process like what is in Third World.

According to the strain theory, some people who are under pressure are forced to show deviant behaviors. This distortion shows itself in variety of forms; one of these forms is marital infidelity. Robert Merton states that this kind of strain is caused by the inability of a person to achieve acceptable social objectives; Albert Cohen considers the category of failure to reach a high position as the cause of strain; Colward \& Ohlin regards lack of illegitimate opportunities to achieve the targets as cause of strain and deviant behaviors. In the present research, the relationship between economic problems and marital infidelity was not approved. This hypothesis was rejected because statistical population includes students that it seems that they do not currently deal with economic pressures and are protected economically by their family.

When the average level of dissatisfaction factors increases, the average rate of marital infidelity will also decrease. In this hypothesis, there was a direct and strong relationship. Robert Burgess and Ronald Akers question Sutherland's theory according to the reinforcement theory stating that continuing or stopping any behavior depends on the encouragement or punishment; it means that encouragement leads in continuing a certain behavior and punishment prevents it. In other words, they claim that association with ones who have deviant behaviors does not make someone deviant. People prefer distortions to conformity when their proportion is more satisfactory to conformity with higher frequency and possibility. According to differential reinforcement, Burgess and Akers believe that if some elements produce reinforcement forces, the element has the highest probability that produces the highest reinforcement in terms of quantity, frequency and probability. Therefore, according to them, intervention of third variable differential reinforcement in differential association environment is the main cause of distortion. As it was approved in this hypothesis, if emotional needs are not met appropriately, it will lead to separation and infidelity and the average rate of marital infidelity will increase. In different perspectives, theories have been raised about the age difference between couples and all of these perspectives have emphasized on this category. As it was approved in this hypothesis, if age factor is not observed, the average rate of marital infidelity will increase.

Intimacy in sexual relations is the result of loving each other. This ability demonstrates deep self-awareness and knowledge of loving another one and romantic relationships act as catalyst.

Having more relations with virtual environments and passing through many customary norms lead to increasing relations out of the customary scope; marital infidelity is one of them. If relations are not controlled in the virtual space, as demonstrated in this study, it can lead to marital infidelity.

If the average rate of low level of religiosity factor increases, the average level of marital infidelity will also increase. Durkheim identified religion as the main source of morality and social cohesion. In his opinion, collecting people in religious ceremonies strengthens religious beliefs and also leads to enthusiastic and warm 
feelings which improve the relationship among people. Hence, religious rituals lead to solidarity of society by strengthening collective beliefs and morals as well as establishing relationships among participants. The function of religion in the society is to integrate and consolidate it. In a book titled "About the definition of the phenomenon of religion", he regards an agent role for religion, it means that practices and religious convictions make social morality consistent. Therefore, the sociology of religion studies the social forces which have overcome the believer as well as conditions in which religious feelings are aroused. According to Durkheim, the evolution of religion parallels and corresponds to the evolution of morality. Along with religions, ethical and legal rules become universal and inclusive. There is something of ethics in religion and something of religion in ethics and the current ethical life is virtually full of religious matters. Since ethics have been considered as sign of religion over the history, it is impossible to be entirely devoid of this character, because in this case, its life will end.

There are various factors affecting marital infidelity which should reach their minimum level because of achieving a healthy marital life

\section{Practical Suggestions}

1. Holding training workshops in order to improve skills of treating husband and wife, sexuality, appropriate and constructive ways of interaction with the opposite sex and to increase awareness about each other's needs and how to respond them properly.

2. Necessity of holding counseling meetings for couples before marriage and giving necessary information to families about the consequences of forced marriages.

3. Training people since adolescence and familiarizing them the needs of opposite sex and also ways of healthy interactions and preparing the youth for appropriate mate selection and healthy marriage through holding training workshops and mass media especially radio and television.

4. Increasing awareness of couples about results and consequences of marital infidelity on family members, and community health and safety through mass media.

5. Promoting the culture of using counseling and social work services and development of telephone lines in order to reduce conflicts, marital disputes, domestic violence and improving the quality of life and mental health of couples.

6. Providing counseling and therapy services to men involved in relationships outside of marriage and also to their spouses and other family members and making efforts to reduce and eliminate psychological, emotional and behavioral problems which have been formed as a result of infidelity.

\section{Research Suggestions}

In order to provide the way for future research on the study of infidelity in marital life, some suggestions are given as follows:

1. Investigating personal, familial and social factors affecting infidelity in women and comparing its result with the findings of the present research.

2. Investigating personal, psychological and sociological features of individuals involved in relationships outside of the marriage and their spouses.

3. The effectiveness of each strategy in community is suggested to be studied and examined to deal with marital infidelity.

\section{References}

Aftab-e Yazd Newspaper (Collected from Information Base of Family Planning).

Ahmadi, H. (2005). Sociology of Deviance, Vol. 1, Tehran: SAMT.

Allen, E. S., \& Atkins, D. C. (2005). The Multidimensional and Developmental Nature of Infidelity: Practical Applications. Journal of Clinical Psychology, 61, 1371-138.

Amato, P. R., \& Rogers, S. J. (1997). A Longitudinal Study of Marital Problems and Subsequent Divorce. Journal of Marriage and the Family, 59, 612-624.

Andre, M. (1999). The Sociology of Family and Marriage, Translated by Ardalan F., Tehran: University of Tehran Press.

Arastekhu, M. (1990). Criticism and Perspective on Social - Scientific Glossary of Terms. Tehran: Gostar Publication. 
Atkins et al. (2005). Infidelity in Couples Seeking Marital Therapy. Journal of Family Psychology, 19, 470-473

Azin, A., \& Pirmohammadi, K. (2009). Investigating the Role of New Media with Emphasis on Satellite and Internet on Cultural Identity of Students. Journal of Social Sciences, 2(2)-156.

Baker, T. (2007). Doing Social Research, Translated by Nayebi. H., Tehran: Ney.

Bazargan, A. (2008). An Introduction to Qualitative and Mixed Research Methods, Vol. 1, Tehran: Didar.

Bell, D. (2001). An Introduction to Cyber-cultures. USA: Routledge.

Bokharayi, A. (2010). Sociology of Social Deviance. Tehran: Payame Noor University.

Cohen, B. (2007). An Introduction to Sociology, Translated by Solasi, M. $12^{\text {th }}$ ed, Tehran: Totiya.

Durkheim, E. (1981). Philosophy and Sociology. Translated by Khamsei, F., Iranian Center for Cultural Studies

Eliade, M. (1994). Study of Religion, Translated by Khoramshahi, B., Tehran: Institute for Humanities and Cultural Studies.

Enayat, H., \& Movahed, M. (2004). Women and Structural Developments of Family in the Age of Globalization. International Journal of Women's Research, 2(2), 153-166.

Harway, M. (2005). Handbook of Couples Therapy. New Jersey: John Wiley \& Sons, Inc., Hoboken.

Jayson, S. (2008). Infidelity is Common Knowledge in USA, Poll Suggests, USA Today, 4D

Jeanfreau, M. M. (2009). A Qualitative Study Investigating the Decision-Making Process of Women's Participation in Marital Infidelity, Manhattan: Kansas.

Kafash, H. (2010). The Proposed Principles and Guidelines and the Mission of Education. Roshd Journal, 2(6), $39-41$.

Khedmatgozar, et al. (2008). Wives' Infidelity, Vol. 1, Tehran: Ghatreh Publications.

Parsa, M. (2004). The New Field of Psychology (20 ed), Tehran: Besat.

Ritzer, G. (2004). Sociological Theory in the Contemporary Era, Translated by Solasi, M. Tehran: Elmi (Scientific) Publications.

Rubinstein Nabarro, N., \& Ivanir, S. (1999). In Terapia Delle Coppie di Mezza eta in Crisiper ana Relazione Extraconiygale.

Salimi, A., \& Davari, M. (2007). Sociology of Deviance, Qom-Zeitun: Research Institute of Hawzah and University.

Sedigh Sarvestani, R. (2004). Social Pathology, Vol. 1, Tehran: A'an Publication.

Sedigh Sarvestani, R. (2010). Social Pathology (Sociology of Deviance) (6th ed). Tehran: SAMT.

Shahghasemi, E. (2014). Network History, Shafaqna Media, History - Network: Notes by Shahghasemi.

Shahsiah et al. (2009). Investigating the Relationship between Sexual Satisfaction and Marital Commitment among Couples in Shahreza City. Journal of Fundamentals of Health.

Shirdel, M. (2004). Investigating Factors which cause Married Men and Women Tend to be Engaged in Sexual Immorality. M. A. Thesis in Counseling Field, Islamic Azad University of Roudehen Branch.

Spring, A. (2001). Wounded Relation, Translated by Faraji, M., Tehran: Ferdowsi Publications.

Tavasoli, G. H. (1993). The Concept of Sociology of Religion, No. 15, Y. 3, Kian Publication.

Ziaei et al. (2008). Investigating Personal and Social Characteristics of Married People with Extramarital Relationships in Tehran and Shiraz Cities from 2006 to 2007, No. 13

\section{Copyrights}

Copyright for this article is retained by the author(s), with first publication rights granted to the journal.

This is an open-access article distributed under the terms and conditions of the Creative Commons Attribution license (http://creativecommons.org/licenses/by/4.0/). 